\title{
Enhanced production of taxadiene in Saccharomyces cerevisiae
}

\author{
Behnaz Nowrouzi ${ }^{1,2 \dagger}$, Rachel A. Li ${ }^{3,4 \dagger}$, Laura E. Walls ${ }^{1,2 \dagger}$, Leo d'Espaux ${ }^{3,4}$, Koray Malcl ${ }^{1,2}$, Lungang Liang ${ }^{1,2}$, \\ Nestor Jonguitud-Borrego $0^{1,2}$, Albert I. Lerma-Escalera ${ }^{5}$, Jose R. Morones-Ramirez ${ }^{5}$, Jay D. Keasling 3,4,6,7,8 \\ and Leonardo Rios-Solis ${ }^{1,2^{*}}$
}

\begin{abstract}
Background: Cost-effective production of the highly effective anti-cancer drug, paclitaxel $\left(\operatorname{Taxo}{ }^{\circledR}\right)$, remains limited despite growing global demands. Low yields of the critical taxadiene precursor remains a key bottleneck in microbial production. In this study, the key challenge of poor taxadiene synthase (TASY) solubility in S. cerevisiae was revealed, and the strains were strategically engineered to relieve this bottleneck.
\end{abstract}

Results: Multi-copy chromosomal integration of TASY harbouring a selection of fusion solubility tags improved taxadiene titres 22 -fold, up to $57 \pm 3 \mathrm{mg} / \mathrm{L}$ at $30^{\circ} \mathrm{C}$ at microscale, compared to expressing a single episomal copy of TASY. The scalability of the process was highlighted through achieving similar titres during scale up to $25 \mathrm{~mL}$ and $250 \mathrm{~mL}$ in shake flask and bioreactor cultivations, respectively at 20 and $30^{\circ} \mathrm{C}$. Maximum taxadiene titres of $129 \pm 15 \mathrm{mg} / \mathrm{L}$ and $127 \mathrm{mg} / \mathrm{L}$ were achieved through shake flask and bioreactor cultivations, respectively, of the optimal strain at a reduced temperature of $20^{\circ} \mathrm{C}$.

Conclusions: The results of this study highlight the benefit of employing a combination of molecular biology and bioprocess tools during synthetic pathway development, with which TASY activity was successfully improved by 6.5fold compared to the highest literature titre in S. cerevisiae cell factories.

Keywords: Taxadiene synthase, Saccharomyces cerevisiae, Paclitaxel, Taxol ${ }^{\mathrm{TM}}$, Yeast metabolic engineering, Minibioreactor

\section{Background}

The highly complex diterpenoid drug Paclitaxel $\left(\operatorname{Taxol}^{\mathrm{TM}}\right)$ first gained FDA approval in 1992 for the treatment of ovarian cancer and has since proven efficacious against a wide range of additional diseases [1]. Direct extraction from its natural source, the bark of Pacific yew (Taxus brevifolia), is both destructive and extremely low-yielding. As a result, paclitaxel is currently produced predominantly by semi-synthesis, involving the

\footnotetext{
*Correspondence: Leo.Rios@ed.ac.uk

${ }^{\dagger}$ Behnaz Nowrouzi, Rachel A. Li and Laura E. Walls contributed equally.

${ }^{1}$ Institute for Bioengineering, School of Engineering, The University of Edinburgh, Edinburgh EH9 3BF, United Kingdom

Full list of author information is available at the end of the article
}

chemical modification of late precursors extracted from plant cell culture. However, as such methods are high in cost and have limited scalability, the development of a more sustainable source is critical to meet growing global demands [2]. One potential solution involves the heterologous expression of the biosynthetic pathway in microbial cell factories. The first committed step in the paclitaxel biosynthetic pathway is the cyclisation of the diterpenoid intermediate, geranylgeranyl diphosphate $(G G P P)$ by taxadiene synthase (TASY), yielding taxa4(5),11(12)-diene (taxadiene) as shown in Fig. 1.

TASY is comprised of three alpha-helical domains; the active site is located within the C-terminal catalytic domain, where GGPP binds and is activated via a cluster of three $\mathrm{Mg}^{2+}$ ions [3]. TASY enzyme activity has been 


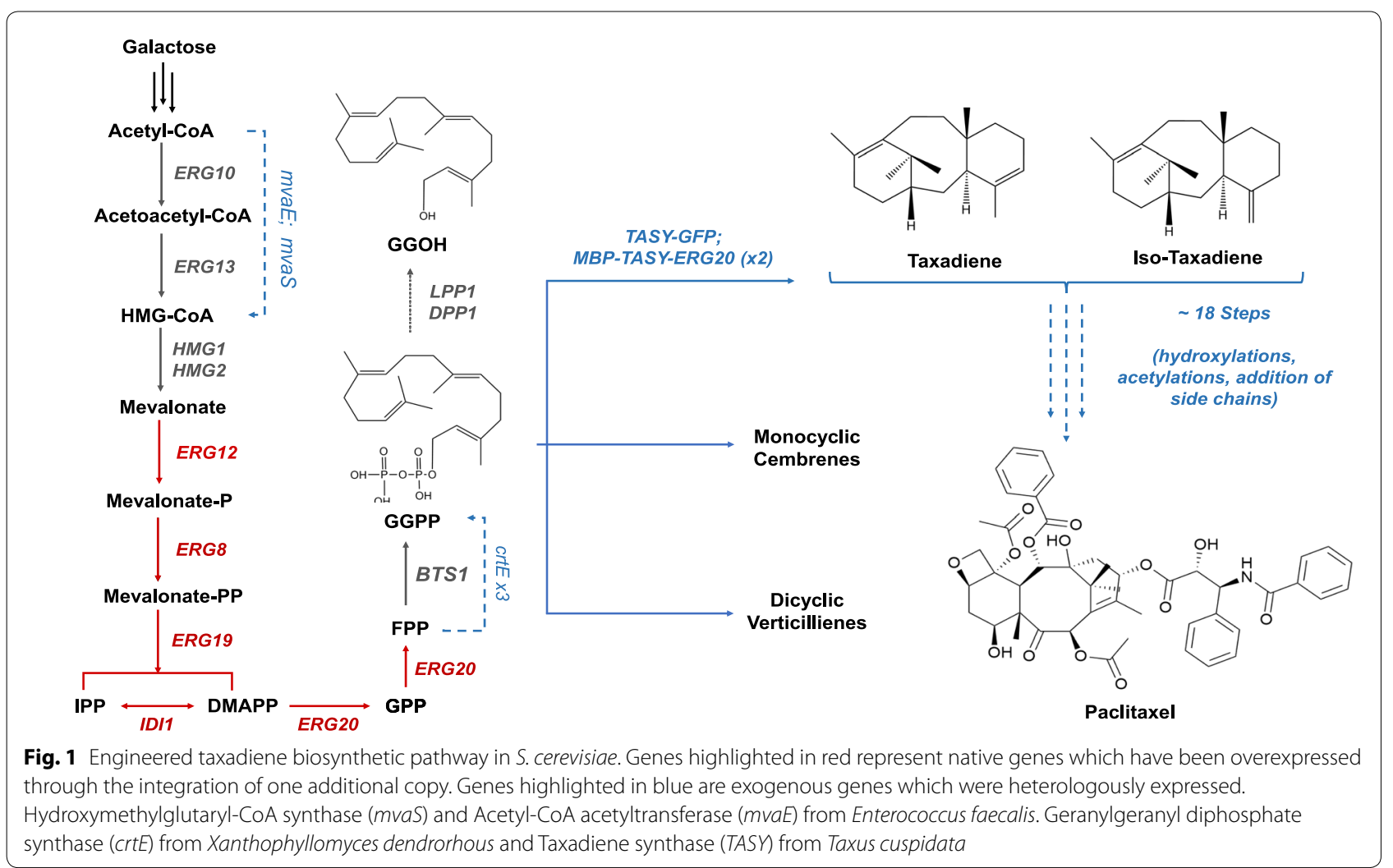

found to be relatively low compared to other terpene synthases, with a 70-fold lower turnover rate than that of a plant abietadiene synthase with high sequence homology [4]. In addition, the volume of the TASY active site is larger than that of taxadiene, contributing to previously observed enzyme promiscuity [5].

The reconstitution of this enzymatic step has been successfully achieved in both E. coli $[6,7]$ and S. cerevisiae $[8,9]$ (Table 1). Through the adoption of a novel multivariate modular approach, Ajikumar et al. [7] improved heterologous taxadiene titres to 300 and $1020 \mathrm{mg} / \mathrm{L}$ in E. coli shake-flask and fed-batch bioreactor cultivations, respectively. However, when the authors expressed the subsequent enzyme, taxadien- $5 \alpha$-hydroxylase, which is a membrane-bound cytochrome $\mathrm{P} 450$, a tenfold reduction in total taxane titre was observed. Membrane-bound cytochrome P450s like taxadien- $5 \alpha$-hydroxylase are estimated to comprise around half of the 19 enzymatic steps in the paclitaxel biosynthetic pathway [10]. As the overexpression of such membrane-bound enzymes is greatly

Table 1 Summary of previous taxadiene biosynthesis yields and conditions using E. coli and S. cerevisiae as microbial hosts

\begin{tabular}{|c|c|c|c|}
\hline Host & Taxadiene concentration & Condition & Reference \\
\hline E. coli & $\sim 300 \mathrm{mg} / \mathrm{L}$ & $2 \mathrm{~mL}$ rich media, $22^{\circ} \mathrm{C}$, IPTG induction, 5 days & [7] \\
\hline E. coli & $1.02 \pm 0.08 \mathrm{~g} / \mathrm{L}$ & $1 \mathrm{~L}$ fed-batch cultivation, $22^{\circ} \mathrm{C}$, IPTG induction & [7] \\
\hline E. coli & $94 \%$ of total product & $\begin{array}{l}\text { IPTG-induced taxadiene synthase purification from E. coli (temperature shift from } \\
37 \text { to } 20^{\circ} \mathrm{C} \text { ). A cell-free assay was conducted afterwards. }\end{array}$ & [14] \\
\hline E. coli & $1.3 \mathrm{mg} / \mathrm{L}$ & $\begin{array}{l}1 \mathrm{~L} \text { Luria-Bertani medium culture, IPTG-induced taxadiene synthase expression } \\
\text { (temperature shift from } 37^{\circ} \mathrm{C} \text { to room temperature) }\end{array}$ & [15] \\
\hline S. cerevisiae & $8.7 \pm 0.85 \mathrm{mg} / \mathrm{L}$ & $100 \mathrm{~mL}$ buffered YPD medium in $500 \mathrm{~mL}$ baffled shake flask, two days, $28^{\circ} \mathrm{C}$ & [8] \\
\hline S. cerevisiae & $20 \mathrm{mg} / \mathrm{L}$ & $5 \mathrm{~mL}$ YP-galactose medium culture & [9] \\
\hline S. cerevisiae & $0.7 \mathrm{mg} / \mathrm{L}$ & $700 \mathrm{~mL}$ rich YP-Galactose medium, 65 h & [13] \\
\hline S. cerevisiae & $1.0 \mathrm{mg} / \mathrm{L}$ & $700 \mathrm{~mL}$ Selective SG-URA medium, $65 \mathrm{~h}$ & [13] \\
\hline
\end{tabular}


hindered in E. coli [11], the construction of the remainder of the pathway is likely to be very challenging in this bacterial host.

The eukaryotic host, S. cerevisiae, on the other hand, possesses the necessary biosynthetic machinery for the expression of such enzymes, including translocation through the endoplasmic reticulum and a native electron transfer machinery [12]. As in E. coli, early attempts to express $T A S Y$ in $S$. cerevisiae were hindered by GGPP availability with a titre of just $122 \mu \mathrm{g} / \mathrm{L}$ in the wild type strain, which was insufficient for taxadiene synthesis [8]. DeJong et al. [13] simultaneously incorporated GGPP synthase (GGPPS) and TASY from Taxus sp. into S. cerevisiae, leading to a taxadiene titre of $1 \mathrm{mg} / \mathrm{L}$. Through the heterologous expression of a Sulfolobus acidocaldarius geranylgeranyl diphosphate synthase (GDS), TASY, and a truncated HMG-CoA, taxadiene titres were later improved to $8.7 \mathrm{mg} / \mathrm{L}$ [8]. A subsequent study focussed on the careful selection of promoters, integration locus, and solubility tags, leading to the highest reported taxadiene titre of $20 \mathrm{mg} / \mathrm{L}$ in yeast [9].

Although taxadiene has been found to be the major product of TASY, with yields over $77 \%$, around 5-13\% of the total taxane product has been found to be the isomer taxa-4(20),11(12)-diene (iso-taxadiene) [14-16]. Small quantities of a product tentatively identified as verticillene and an additional taxadiene isomer (taxa3(4),11(12)-diene) have also been detected in E. coli and Nicotiana benthamiana $[16,17]$.

The metabolic pathway of paclitaxel is highly complex and development of an alternative recombinant production route remains in the preliminary stages. Despite this, substantial advancements in synthetic biology have been achieved recently [18]. Through the application of such tools, there is great potential to accelerate the development of a microbial paclitaxel biosynthetic pathway. This study focussed on the optimisation of TASY enzyme performance in S. cerevisiae to alleviate a key early pathway bottleneck. The effect of a number of factors including TASY truncation length, selected promoter and chromosomal gene copy number on pathway expression were evaluated. Cultivation conditions such as culture temperature and exogenous cofactor availability were also considered.

\section{Results and discussion}

\section{Optimisation of taxadiene titre using episomal TASY expression}

Four key parameters with the potential to affect final taxadiene titre were examined using a high-copy (2-micron) plasmid in the mGty116 S. cerevisiae strain. Such parameters included the selected promoter, cultivation temperature, cofactor $\left(\mathrm{Mg}^{2+}\right)$ concentration, and TASY sequence truncation. The results are summarised in Fig. 2.

In this study, the performance of four constitutive promoters of increasing strength, pREV1, pSAC6, pRPL18B and pTDH3 [19] were compared to that of the strong inducible GAL1 promoter in S. cerevisiae, grown in SDGD-Leu media (Fig. 2a). Performance of the highest strength constitutive TDH3 and inducible GAL1 promoters was highly similar with titres of $4.1 \pm 0.3$ and $4.0 \pm 0.3 \mathrm{mg} / \mathrm{L}$, respectively. Decreasing promoter strength did not improve taxadiene titres, which were 1.6, 2.9 and 8.2-fold lower for the weaker, RPL118B, SAC6 and REV1 promoters, respectively. As changing the promoter from the inducible GAL1 promoter resulted in no further improvement in taxadiene titre (Fig. 2a), pGAL1 was selected for subsequent studies.

The growth temperature was found to have an important effect on taxadiene titre as shown in Fig. 2b. Reducing the cultivation temperature from $30{ }^{\circ} \mathrm{C}$ to $20{ }^{\circ} \mathrm{C}$ resulted in a 3.0-fold increase in final taxadiene titre to $8 \pm 0.1 \mathrm{mg} / \mathrm{L}$. However, at the lower temperature biomass accumulation was also reduced, with a final $\mathrm{OD}_{600}$ of 2.90 , compared to 4.5 at $30{ }^{\circ} \mathrm{C}$. The temperature of $20^{\circ} \mathrm{C}$ selected in this study was based on the findings of a recent study by Abdallah et al. [21], showing that TASY expression in B. subtilis was greatly improved at $20{ }^{\circ} \mathrm{C}$, as opposed to higher temperatures. This was in agreement with previous results where heterologous expression of TASY in E. coli [20] and Bacillus subtilis [21] has also been found to be sensitive to culture temperature. Productivity analysis over a broad temperature range $\left(12-37{ }^{\circ} \mathrm{C}\right.$ ) revealed a temperature optimum of $22{ }^{\circ} \mathrm{C}$ for both species [20]. In addition, the highest reported titre of $1020 \mathrm{mg} / \mathrm{L}$ was achieved in E. coli cultures at a temperature of $22^{\circ} \mathrm{C}$ [7].

TASY relies on the metal ion co-factor, $\mathrm{Mg}^{2+}$, for activation and substrate orientation within the active site [22]. In a recent study by Tashiro et al. [23], $\mathrm{MgCl}_{2}$ supplementation was found to improve activity of an alternative diterpene synthase, pinene synthase, up to $20 \mathrm{mM}$ in E. coli. As the concentration of $\mathrm{Mg}^{2+}$ in the SDGDLeu medium was around $0.8 \mathrm{mM}$, it was hypothesised to be rate limiting. However, supplementation of the cultivation medium with additional $\mathrm{MgCl}_{2}$ did not significantly improve taxadiene titres at 20 or $30{ }^{\circ} \mathrm{C}$ in this study (Fig. 2c). Consequently, additional $\mathrm{MgCl}_{2}$ supplementation was not deemed necessary for subsequent experiments.

The native TASY gene encodes 862 amino acids, including a putative $\mathrm{N}$-terminal sequence of $\sim 137$ residues which is cleaved upon maturation in plastids [3]. Removal of this sequence was found to reduce inclusion 

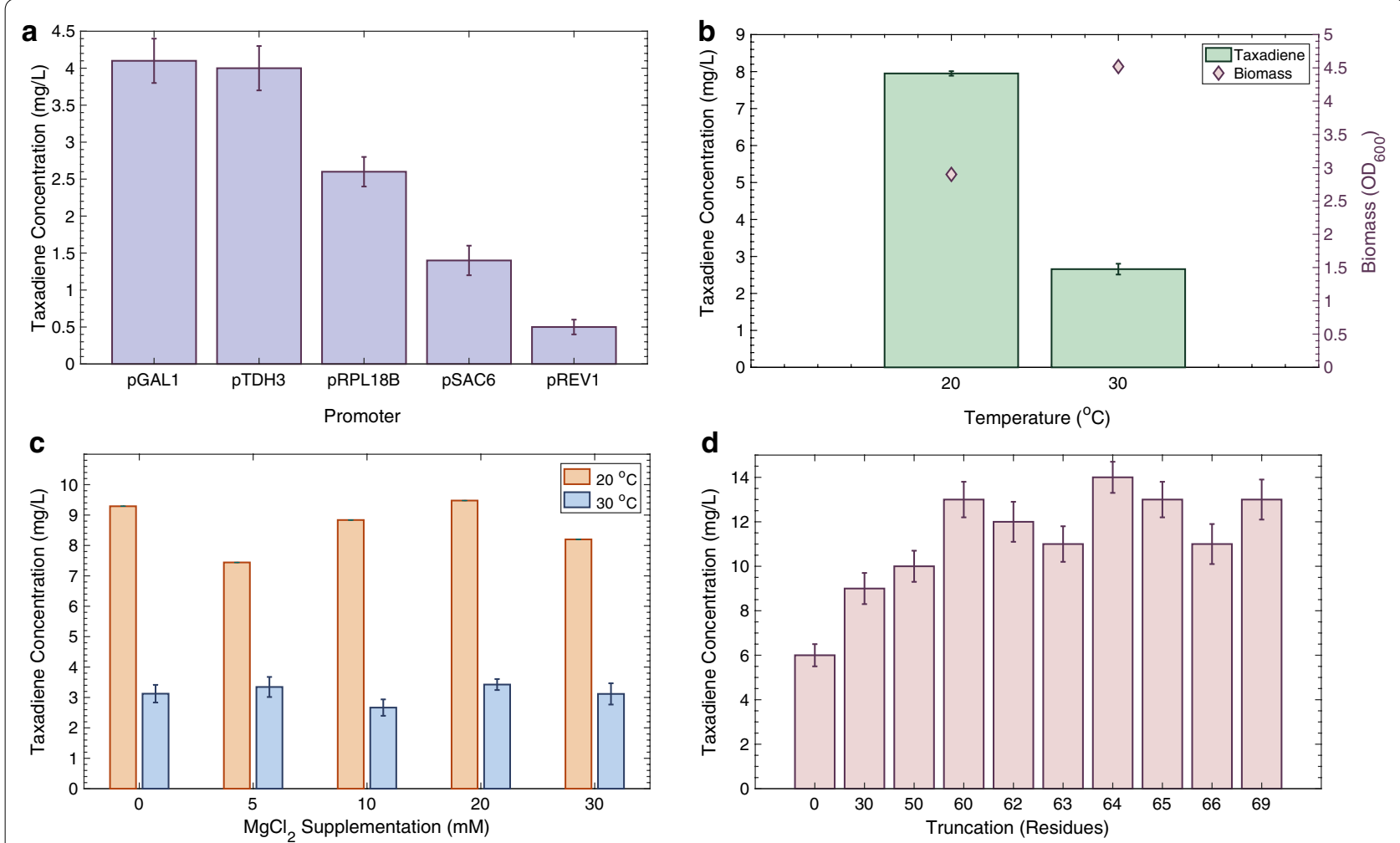

Fig. 2 Optimisation of taxadiene titres using episomal TASY expression. a Effect of promoter on taxadiene concentration produced by cells incubated at $30^{\circ} \mathrm{C}$. $\mathbf{b}$ Effect of cultivation temperature on taxadiene titre. $\mathbf{c}$ Effect of cofactor $\left(\mathrm{Mg}^{2+}\right)$ availability at 20 and $30^{\circ} \mathrm{C}$. $\mathbf{d}$ Effect of gene truncation length for taxadiene production at $20^{\circ} \mathrm{C}$. Values shown are mean \pm standard deviation for $96-\mathrm{h}$ triplicate cultivations

body formation, while increasing active and soluble protein production in E. coli $[3,14]$ In order to determine the optimal protein length for TASY expression in S. cerevisiae with the aim to achieve an improved TASY solubility, a range of truncation lengths were tested (Fig. 2d). Increasing truncation length up to 60 residues improved taxadiene production from $6.0 \pm 0.5$ to $13.0 \pm 0.8 \mathrm{mg} / \mathrm{L}$ as shown in Fig. 2d. In variants harbouring longer truncations, no further improvement in taxadiene titre was observed. The TASY variant with a 60-residue truncation was therefore selected for subsequent experiments. These results were in agreement with previous works where truncations of 60 or 79 residues yielded active protein and reduced inclusion body formation, whilst truncations of 93 or more residues produced inactive protein in E. coli [14].

\section{Chromosomal integration of TASY \\ Comparing episomal and chromosomal expression}

Plasmid-based systems rely on the use of expensive selective media, limiting their industrial relevance. In a previous study, a single copy of the TASY gene was chromosomally integrated into the mGty116 strain. Cultivation of the resulting LRS2 (pTDH3-TASY-tADH1) strain at $30{ }^{\circ} \mathrm{C}$ resulted in a taxadiene titre of $2.6 \pm 0.4 \mathrm{mg} / \mathrm{L}$ [9]. Interestingly, this titre was comparable to the $2.7 \pm 0.2 \mathrm{mg} / \mathrm{L}$ achieved using the high-copy 2-micron plasmid system in this study (Fig. 2b). The effect of stable chromosomal TASY integration in yeast was therefore investigated in the mGty116 strain of this study. In order to visualise functional TASY expression, TASY was tagged with a C-terminus GFP reporter gene (strain LRS3). Cultivation of this strain yielded $12 \pm 1 \mathrm{mg} / \mathrm{L}$ of taxadiene at $30^{\circ} \mathrm{C}, 4.7$-fold higher than that of the LRS2 strain. This was also comparable to the optimal plasmidbased titre of $13 \pm 1 \mathrm{mg} / \mathrm{L}$ achieved at the lower temperature of $20^{\circ} \mathrm{C}$ (Fig. 2d). This suggested that chromosomal integration improved taxadiene titre in comparison to episomal expression.

\section{Effect of gene copy number and solubility tags}

Fusion tags are often used to improve protein expression and solubility [24]. A recent study using a range of tags, revealed that maltose binding protein (MBP), had the greatest positive impact on TASY solubility and activity in S. cerevisiae [9]. Prenyltransferaseterpene synthase fusion proteins have also been found to greatly improve terpene production $[25,26]$. The 
prenyltransferase, farnesyl diphosphate synthase, encoded by ERG20 catalyses the formation of the geranyl diphosphate (GPP) and farnesyl diphosphate (FPP) metabolites, two key enzymatic steps in the mevalonate pathway (Fig. 1). ERG20 has been reported to significantly improve isoprenoid concentration when used as a fusion protein with terpene synthases, potentially promoting enzyme solubility as well as increasing the pool of the isoprenoid precursor farnesyl diphosphate [25, 27]. Deng et al. [26] showed that the fusion of a mutant variant of ERG20 to (S)-linalool synthase

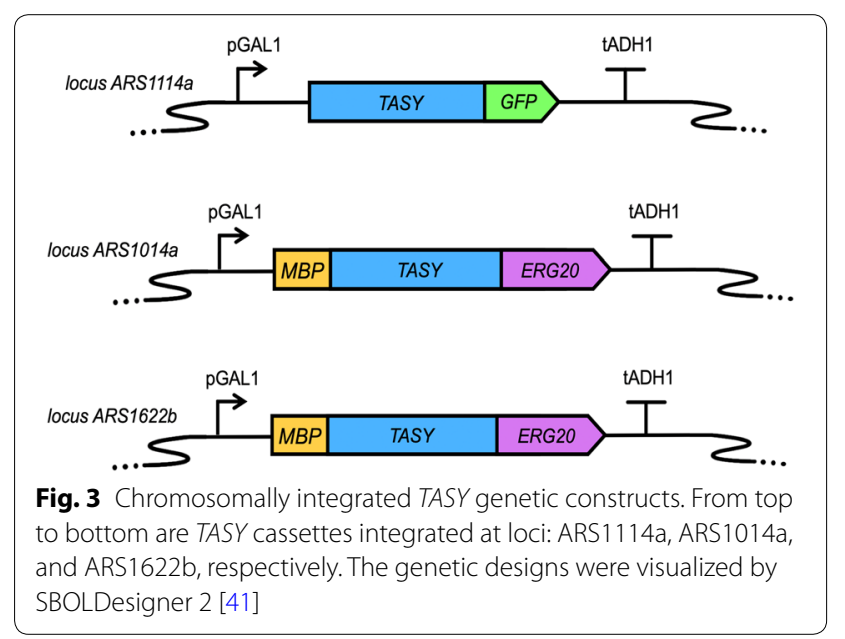

improved the productivity by around $70 \%$ compared to independent integration of the two genes in S. cerevisiae. Hence, a cassette containing an $\mathrm{N}$-terminal yeast codon-optimised MBP tagged TASY-ERG20* (F96C; [25]) fusion gene was developed with the dual aim of increasing precursor availability and improving TASY solubility. This cassette was chromosomally integrated into locus ARS1014a of LRS3 to yield strain LRS4. The integration of a second copy of this dual-tagged TASY in locus ARS1622b resulted in strain LRS5 $(1 \times T A S Y$ GFP, $2 \times$ MBP-TASY-ERG20*, Fig. 3). These two loci were previously reported to show high expression rate as tested with a GFP reporter [9].

Cultivation of the newly constructed LRS4 strain expressing two copies of TASY resulted in an over three-fold improvement in taxadiene titre to $40 \pm 3 \mathrm{mg} / \mathrm{L}$ at microscale. Through cultivation of the subsequent LRS5 strain, taxadiene titres were further enhanced to $57 \pm 3 \mathrm{mg} / \mathrm{L}$ at $30{ }^{\circ} \mathrm{C}$, the highest titre in yeast reported to date at microscale level (Fig. 4).

Through effective copy number optimisation and the use of MBP and GFP tags along with an ERG20 fusion, taxadiene production was enhanced up to 22 -fold in $S$. cerevisiae (Fig. 4). This was likely the result of improved protein expression and solubility, as well as increased FPP availability for the synthetic pathway [27]. Nevertheless, fluorescent visualisation still showed substantial spotted subcellular localization (Additional file 1:

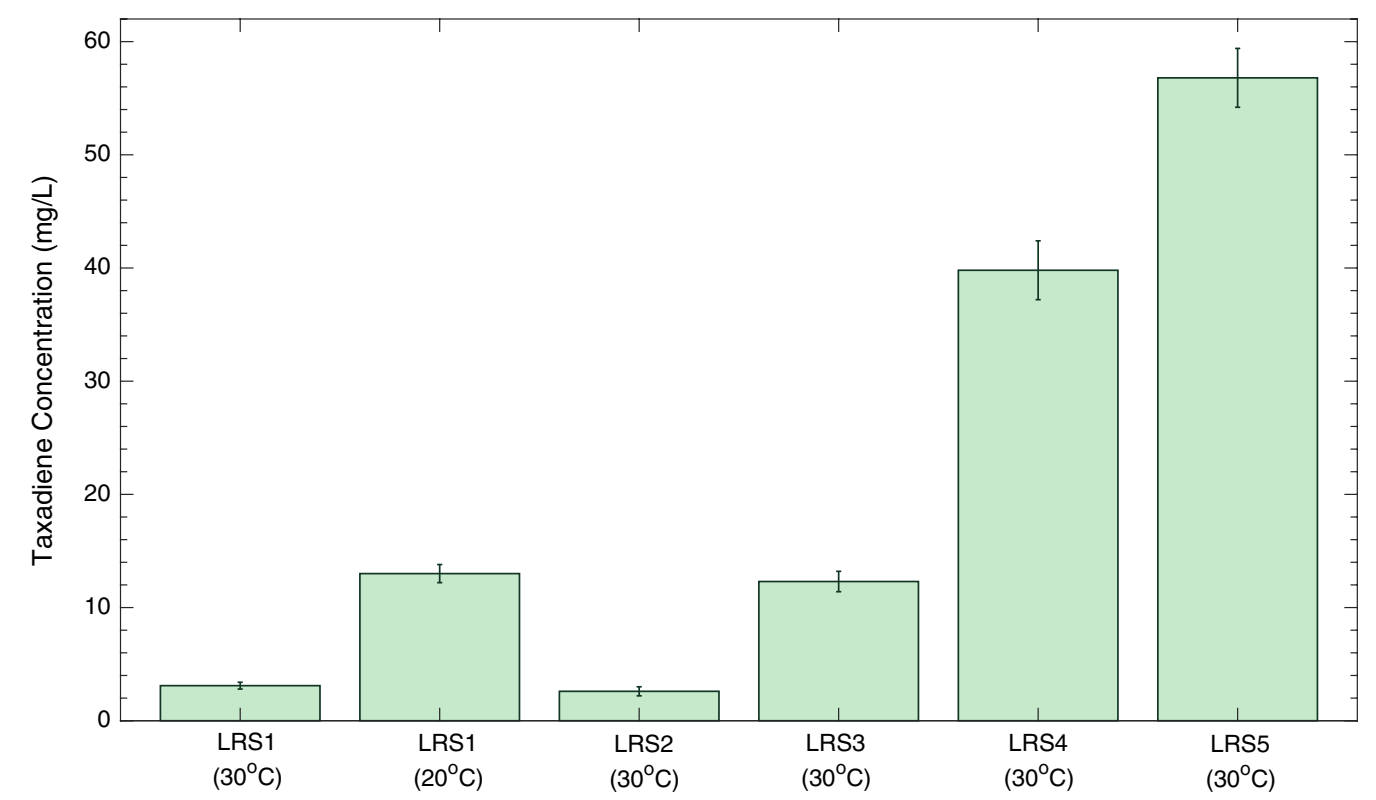

Fig. 4 Summary of taxadiene titers microscale optimisation study. LRS1 indicates titers resulting from episomal TASY expression using the high copy 2-micron plasmid (LRS1) at 30 and $20^{\circ} \mathrm{C}$, respectively. The other titers are from strains with chromosomally integrated TASY variants: LRS2 (TDH3P-TASY-ADH1t), LRS3 (TASY-GFP), LRS4 (TASY-GFP; MBP-TASY-ERG20*) and LRS5 (TASY-GFP; MBP-TASY-ERG20*; MBP-TASY-ERG20*), respectively, grown at $30^{\circ} \mathrm{C}$ 
Figure S1), which was consistent with a previous study highlighting the poor solubility of TASY [9].

\section{Taxadiene production scale-up Minor product characterisation at increased scale under different temperatures}

In order to investigate process scalability, the optimised LRS5 strain was subsequently cultivated in $250-\mathrm{mL}$ shake flasks ( $25 \mathrm{ml}$ working volume). The effect of temperature on chromosomal TASY expression by the optimised strain was also assessed through cultivation at both $20^{\circ} \mathrm{C}$ and $30^{\circ} \mathrm{C}$. The results of this experiment are summarised in Fig. 5.

The final taxadiene titre at $20{ }^{\circ} \mathrm{C}$ was $129 \pm 15 \mathrm{mg} / \mathrm{L}$, representing an almost 6.5 -fold improvement over the highest reported titre [8]. The final titre at $30{ }^{\circ} \mathrm{C}$ was $56.9 \pm 2.7 \mathrm{mg} / \mathrm{L}$, which was comparable to the $57 \pm 3 \mathrm{mg} / \mathrm{L}$ obtained in the smaller scale cultivations (Fig. 4). This represented a 2.3-fold lower taxadiene titre at $30{ }^{\circ} \mathrm{C}$ compared to $20{ }^{\circ} \mathrm{C}$, indicating that despite the addition of solubility tags, further optimisation is likely to be necessary at higher growth temperatures. Interestingly, biomass accumulation was very similar for the strain in nutrient rich YPG medium, with final $\mathrm{OD}_{600}$ values of $29 \pm 1$ and $31 \pm 1$ at 20 and $30{ }^{\circ} \mathrm{C}$, respectively (Fig. 5b). In selective, dropout medium (SDGD-Leu, Fig. 2b), however, a $36 \%$ lower final biomass yield was achieved at $20{ }^{\circ} \mathrm{C}$. The more prominent effect of cultivation temperature on growth rate observed in the selective medium was likely the result of an increased metabolic burden associated with plasmid expression coupled with the reduced nutrient availability in SDGD-Leu medium compared to YPG.

Although taxadiene was the major product under all conditions studied, additional side products were also generated, due to TASY promiscuity [28]. At this scale, further characterisation of such side products was performed through a detailed analysis of gas chromatography (Fig. 6) and mass spectrometry data (Additional file 1: Figure S2).

In addition to taxadiene, which was eluted at $8.10 \mathrm{~min}$ (Additional file 1: Figure S2-D), a further five diterpene products were detected as shown in Fig. 6 . The mass spectra of the peaks at 7.43 and $7.88 \mathrm{~min}$ (Additional file 1: Figures S2-A, C) showed a high degree of similarity to compounds previously identified as verticillene and the taxadiene isomer, taxa-4(20),11(12)-diene (iso-taxadiene), respectively $[14,16]$. Verticillene is a bridged bicycle product formed as part of a series of carbocation-mediated cyclisations involved in taxadiene synthesis from acyclic GGPP [29]. An additional two diterpene compounds, Diterpene 1 and Diterpene 2 (Additional file 1: Figures S2-B and S2-E) were observed at 7.78 and $8.16 \mathrm{~min}$, respectively. The mass spectrum of diterpene 1 closely resembled cembrene-type diterpene (cembrene A) produced by neocembrene synthase in S. cerevisiae [30]. The cyclisation of GGPP to taxadiene involves production of a cembrenyl intermediate [31]. The relatively high degree of similarity suggests the compound observed in this study could potentially be a side
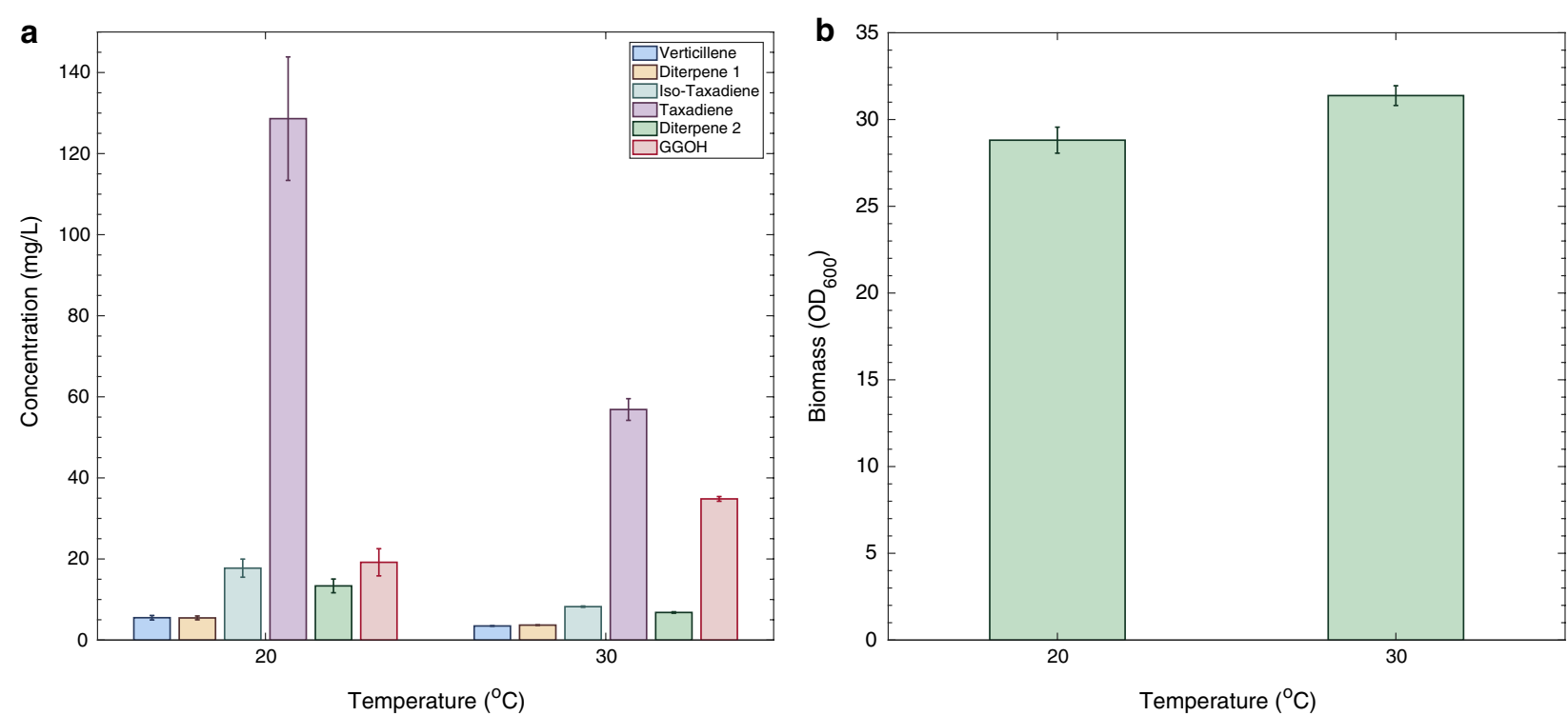

Fig. 5 Effect of temperature on LRS5 performance in shake flasks. LRS5 was cultivated in $250 \mathrm{~mL}$ shake flasks in YPG media at 20 or $30{ }^{\circ} \mathrm{C}$. Taxane accumulation (a) and yeast growth (b) were evaluated after $72 \mathrm{~h}$ of cultivation. Error bars represent \pm standard deviation for triplicate cultivations 


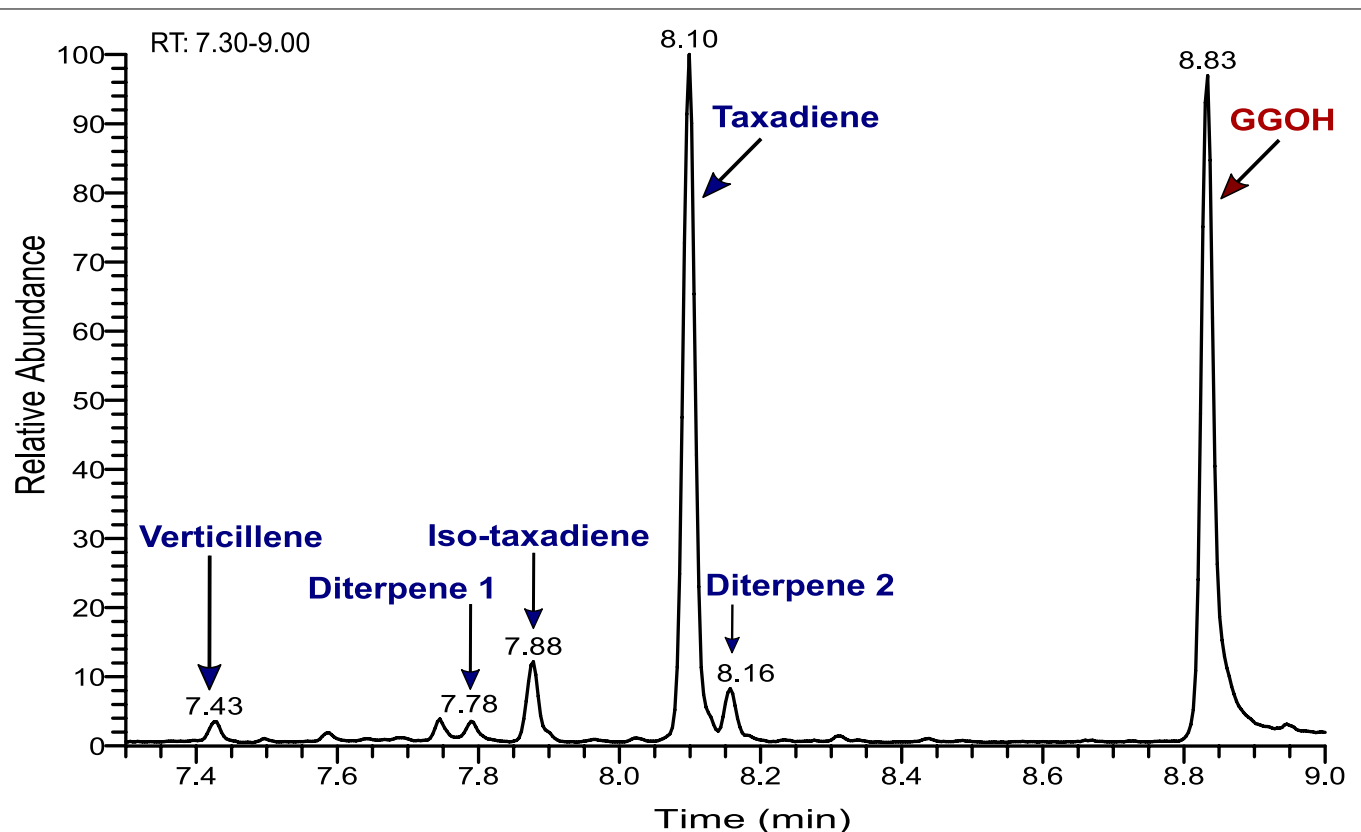

Fig. 6 LRS5 gas chromatogram. Results show products produced by LRS5 during the $30^{\circ} \mathrm{C}$ shake flask cultivation

product of this cyclisation step. However, further characterisation is needed to confirm this. The mass spectrum and elution order of diterpene 2 was very similar to that of a novel diterpene product of TASY expression in Nicotiana benthamiana [17]. Production of geranylgeraniol (GGOH) (8.83 min; Additional file 1: Figure S2-F) was also confirmed using a pure analytical standard. Although GGOH is formed naturally by S. cerevisiae through the degradation of GGPP by endogenous phosphatases, titres are typically too low to detect [32]. Its overproduction here indicates that early work to overexpress the mevalonate pathway was successful, however, taxadiene titres could be improved further through pathway optimisation. Huang et al. showed that truncated TASY has dual activity, which besides taxadiene isomers, can also synthesize sesquiterpenes using FPP as the substrate instead of GGPP [33]. Here, in addition to the diterpene products, a number of additional potential terpenoid side-products were detected between 4.36 and 6.38 min (Additional file 1: Figures S3 and S4). Although TASY enzyme has been evolved to reduce its promiscuity through direct intramolecular proton transfer in the last step to taxadiene formation, it is prone to side product generation due to carbocations involved in GGPP to taxadiene cyclisation [28]. Despite this, to minimise the production of these side products, increasing the metabolic flux towards GGPP formation seems necessary. Although paclitaxel biosynthesis can also proceed through iso-taxadiene, taxadiene is the main precursor in paclitaxel biosynthesis pathway [16]. However, to increase the selectivity of TASY towards taxadiene formation, enzyme engineering approaches are essential. This can be achieved through rational and evolutionary approaches due to availability of its protein structure [3, 5]. For instance, Edgar et al. improved the yield and selectivity for iso-taxadiene by 2.4 -fold and reduced taxadiene production [34].

\section{Scale-up using a mini-bioreactor system}

A tenfold scale-up of the LRS5 cultivation was used to assess performance under industrial conditions for taxadiene production. A 500-mL MiniBio bioreactor (Applikon, UK) was employed for this study. This system possesses the online monitoring and control capabilities of larger-scale bioreactors, allowing industrial scale cultivation conditions to be effectively mimicked whilst conserving valuable resources. The results of the bioreactor-scale runs are summarised in Fig. 7.

Following $72 \mathrm{~h}$ of cultivation, the $\mathrm{OD}_{600}$ values of the 20 and $30{ }^{\circ} \mathrm{C}$ cultivations were 10.6 and 14.6 respectively as shown in Fig. 7a and c. This was significantly lower than the $29 \pm 1$ and $31 \pm 1$ obtained at shake flask scale (Fig. 5b). Taxadiene titres were also lower in the bioreactor studies at 27 and $35 \mathrm{mg} / \mathrm{L}$ compared to 129 and $57 \mathrm{mg} / \mathrm{L}$ for the equivalent 20 and $30{ }^{\circ} \mathrm{C}$ shake flask cultures. Despite this, following a further $30 \mathrm{~h}$ of cultivation, the stationary phase of growth was reached, and a maximum taxadiene titre of $53 \mathrm{mg} / \mathrm{L}$ was attained in the $30^{\circ} \mathrm{C}$ reactor. This was highly comparable to those obtained in the 72-h microscale (Fig. 4) and shake flask (Fig. 5a) 

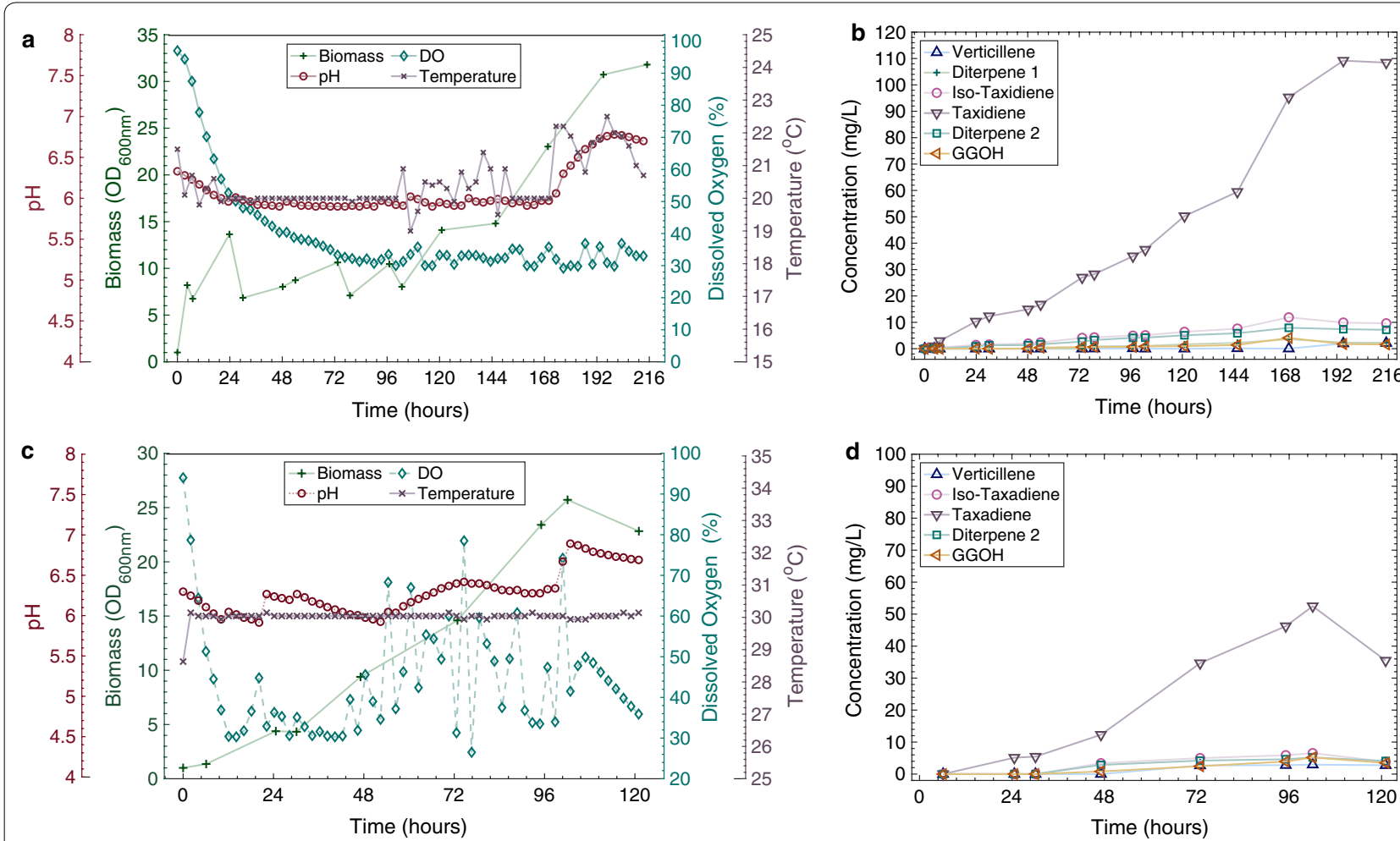

Fig. 7 Bioreactor studies results and respective taxane concentration kinetics at $20^{\circ} \mathrm{C}(\mathbf{a}, \mathbf{b})$ and at $30^{\circ} \mathrm{C}(\mathbf{c}, \mathbf{d})$. LRS5 was cultivated in an Applikon MiniBio 500 bioreactor in yeast extract (1\%), peptone (2\%), galactose (2\%). The pH and dissolved oxygen were monitored online and controlled to set points of 6 and $30 \%$, respectively online

cultivations. A higher taxadiene titre of $109 \mathrm{mg} / \mathrm{L}$ was achieved in the $20{ }^{\circ} \mathrm{C}$ bioreactor, however, a bioreactor run time of $195 \mathrm{~h}$ was required. Interestingly, production of the endogenous GGOH side product was dramatically reduced at the increased scale with maximum titres of 4 and $5 \mathrm{mg} / \mathrm{L}$ (Fig. 7b, d) compared to $19 \pm 3$ and $35 \pm 1 \mathrm{mg} / \mathrm{L}$ for the equivalent 20 and $30{ }^{\circ} \mathrm{C}$ shake flask studies (Fig. 5a).

Unlike prokaryotes, eukaryotic yeast cells have evolved to store hydrophobic compounds within specialised organelles (liquid droplets) [35]. As a result, it was hypothesised that additional taxadiene may be present within the yeast cells. An investigation into intracellular taxane production was therefore performed on samples taken from the higher-yielding $20{ }^{\circ} \mathrm{C}$ bioreactor cultivation as summarised in Fig. 8.

In the first $168 \mathrm{~h}$ of the cultivation, both extracellular and intracellular taxadiene accumulation increased (Fig. 8). In the subsequent $48 \mathrm{~h}$, a sharp decline in intracellular taxadiene from 31 to $11 \mathrm{mg} / \mathrm{L}$ was observed. This was coupled with an increase in extracellular taxadiene from 95 to $109 \mathrm{mg} / \mathrm{L}$ while the total taxadiene concentration remained similar between 119 and $127 \mathrm{mg} / \mathrm{L}$ (Fig. 8). This suggested that the increase in extracellular taxadiene

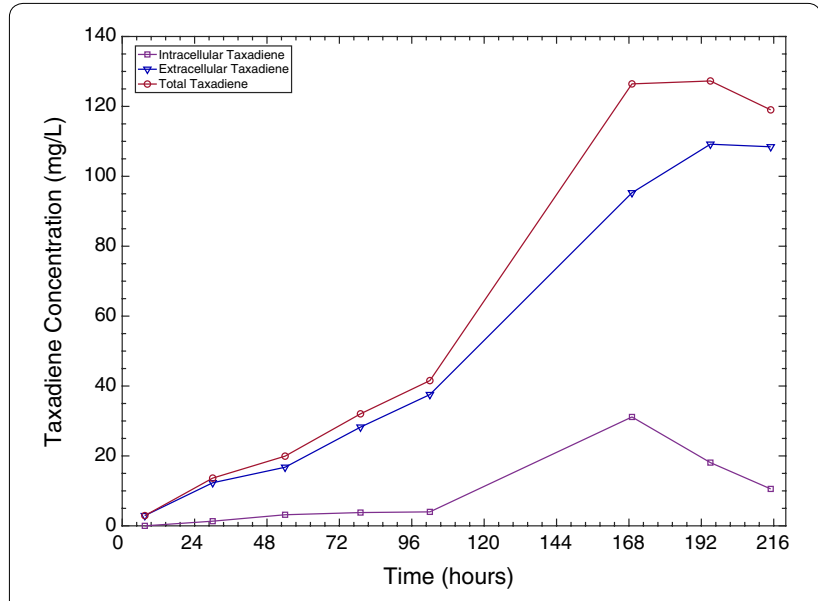

Fig. 8 Kinetics of intracellular and total taxadiene titres in high-yielding $20^{\circ} \mathrm{C}$ bioreactor cultivation

concentration observed in the last $48 \mathrm{~h}$ was likely largely due to taxadiene secretion rather than additional taxadiene biosynthesis.

The temperature can impact gene expression and protein folding [20]. Also, it has been shown that at a lower 
temperature, mevalonate pathway genes are overexpressed in S. cerevisiae [36], providing more precursors to TASY. It is also likely that lower temperature has influenced TASY solubility, as was shown in previous studies for terpene synthase expression in E. coli [37, 38]. Moreover, as there was a concurrent decrease in the titre of GGPP side product (GGOH) at $20{ }^{\circ} \mathrm{C}$, at both shake flask and bioreactor cultivations (Figs. $5 \mathrm{a}$ and $7 \mathrm{~b}$ ), it can be postulated that TASY activity was improved at lower temperature, resulting in more rapid GGPP consumption and reducing its accumulation to become degraded to $\mathrm{GGOH}$ by endogenous phosphatases [32]. In line with these facts, a lower cultivation temperature of $20^{\circ} \mathrm{C}$ was found to improve TASY performance with higher taxadiene titres being obtained under all the conditions investigated in this study. However, the kinetic analysis revealed a strong positive correlation between biomass and product accumulation at both 20 and $30{ }^{\circ} \mathrm{C}$ (Pearson's $\mathrm{R}=0.916$ and 0.974 , respectively). As the growth rate of LRS5 decreased with temperature, longer cultivation time was required at $20{ }^{\circ} \mathrm{C}$. This was exacerbated at larger scale, where cultivation time was tripled (Fig. 7a). Although careful optimisation yielded substantial improvements in TASY productivity in this study, the discrepancies between the optimal temperature for the enzyme and host growth remain a challenge. The optimisation of copy number and protein tag combination improved taxadiene titres dramatically in this study. However, the higher titres obtained at reduced temperature indicate further optimisation is needed at the optimal growth temperature of $30^{\circ} \mathrm{C}$.

\section{Conclusions}

This study reports the successful optimisation of taxadiene biosynthesis in a Saccharomyces cerevisiae microbial chassis. Low expression and poor solubility of taxadiene synthase (TASY) were identified as critical bottlenecks. This was alleviated through multi-copy chromosomal integration of $T A S Y$ with a combination of fusion protein tags, improving taxadiene titres 22 -fold to $57 \pm 3 \mathrm{mg} / \mathrm{L}$ at $30{ }^{\circ} \mathrm{C}$. TASY performance was found to be temperature-dependant, with a maximum taxadiene titre of $129 \pm 15 \mathrm{mg} / \mathrm{L}$ at $20{ }^{\circ} \mathrm{C}$. Similar titres were achieved at larger scale as well, highlighting the scalability of the bioprocess, and representing a 6.5 -fold improvement on the highest literature titre.

This work highlights the benefit of multifactorial approach to biosynthetic pathway optimisation, where a combination of molecular biology tools and bioprocessing approaches were employed. Although the current study presents significant progress in taxadiene biosynthesis, several tasks remain to improve the expression of taxadiene synthase at $30^{\circ} \mathrm{C}$ to allow for further paclitaxel biosynthetic pathway development in S. cerevisiae.

\section{Methods \\ Yeast strains and media}

The parent $S$. cerevisiae strain used for episomal expression and integration studies was GTy116 (MATa, leu23, 112::HIS3MX6-GAL1p-ERG19/GAL10p-ERG8; ura3-52::URA3-GAL1p-MvaSA110G/GAL10pMvaE (codon-optimised); his3 $1::$ hphMX4-GAL1pERG12/GAL10p-IDI1;trp1-289::TRP1_pGAL1-CrtE(X. den)/GAL10p-ERG20; YPRCdelta15::NatMX-GAL1pCrtE(opt)/GAL10p-CrtE) described previously by [9], originating from CEN.PK2-1C (EUROSCARF collection). The $U R A 3$ marker of this strain was further restored to give mGty116. All chemicals and reagents were sourced from Sigma-Aldrich at the highest available purity unless otherwise stated. Episomal expression systems made use of synthetic defined medium minus uracil (CSM-Ura and CSM-Leu, Sunrise Science Products) depending on the selection marker used. These were supplemented with $2 \%$ $(\mathrm{w} / \mathrm{v})$ glucose (SDD-Leu), 2\% (w/v) galactose (SDG-Leu) or a $1.8 \%(\mathrm{w} / \mathrm{v})$ galactose, $0.2 \%(\mathrm{w} / \mathrm{v})$ glucose mixture (SDGD-Leu). For cultivation of strains harbouring chromosomally integrated genes, a medium containing yeast extract $(1 \%(\mathrm{w} / \mathrm{v}))$ and peptone $(2 \%(\mathrm{w} / \mathrm{v}))$, supplemented with $2 \%(\mathrm{w} / \mathrm{v})$ glucose (YPD), galactose (YPG) or $1.8 \%$ $(\mathrm{w} / \mathrm{v})$ galactose and $0.2 \%(\mathrm{w} / \mathrm{v})$ glucose mixture (YPGD) were used.

\section{Yeast transformation and strain construction}

Episomal expression was achieved through transforming $S$. cerevisiae with high copy 2-micron plasmids harbouring TASY and a LEU2 selection marker (Additional file 1: Table S1). The standard LiAc/SS carrier DNA/PEG method was used for all transformations [39]. Chromosomal integration was performed using a cloning free, Cas9-mediated homologous recombination method [9]. High copy number, Cas9-sgRNA 2-micron plasmids harbouring a URA3 selection marker derived from pRS426 were used. The gene cassettes were designed using an online tool, CASdesigner. Chromosomal integration at the target site was confirmed by colony PCR and Sanger sequencing (Genewiz Inc., USA; Edinburgh Genomics, UK). Plasmid curing was subsequently performed on successful colonies through sequential culture on YPD agar medium until no growth was observed on concurrent SDD-Leu agar plates.

The strains used in this study are summarised in Table 2 and plasmid, primer and tag sequences are tabulated in Additional file 1: Tables S1-3. All DNA sequences were synthesised by IDT (Integrated DNA Technologies, Inc.). 
A TASY sequence from Taxus cuspidata was codon optimised for expression in S. cerevisiae. DNA amplification was performed using Phusion Flash High-Fidelity PCR Master Mix (Thermo Fisher Scientific). Promoter and terminator sequences native to the yeast genome were selected [19].

\section{Optimisation of taxadiene producton at microscale}

Preliminary microscale episomal expression studies involved $5 \mathrm{ml}$ cultures of the mGTy116 strain harbouring selected high-copy 2-micron plasmids as shown in Additional file 1: Table S1. Inocula were prepared through transferring a single yeast colony to $5 \mathrm{ml}$ of SDD-Leu medium, followed by incubation overnight at $30{ }^{\circ} \mathrm{C}$. Aliquots of the inoculum were diluted with SDGD-Leu medium to give an initial $\mathrm{OD}_{600}=0.5$. The yeast cultures were incubated at 20 or $30{ }^{\circ} \mathrm{C}$ and $200 \mathrm{rpm}$ for $96 \mathrm{~h}$. To minimise air-stripping of the volatile terpene products, a biphasic liquid-liquid system was used through the addition of a $10 \%(\mathrm{v} / \mathrm{v})$ dodecane overlay after $24 \mathrm{~h}$ of cultivation. At the end of the cultivation, the resulting cultures were centrifuged, and the organic dodecane layer was extracted for GC-MS analysis. Microscale culture of the strains harbouring chromosomally integrated genes was done in a similar way as for episomal expression, except that YPD and YPGD media were used for the inoculum and production cultures, respectively.

\section{Shake flask cultivations}

Single LRS5 colonies were transferred from YPD agar to $5 \mathrm{~mL}$ YPD medium and incubated at $30{ }^{\circ} \mathrm{C}$ and $250 \mathrm{rpm}$ overnight. Aliquots of these cultures were then used to inoculate $20 \mathrm{~mL}$ YPG in $250 \mathrm{~mL}$ shake flasks to an $\mathrm{OD}_{600}=1$. A $20 \%(v / v)$ dodecane overlay was used giving a total working volume of $25 \mathrm{~mL}$. The resulting cultures were incubated at 20 or $30^{\circ} \mathrm{C}$ and $250 \mathrm{rpm}$ for $72 \mathrm{~h}$. At the end of the cultivation, the dodecane overlay was extracted for GC-MS analysis. The final biomass was measured at an optical density of $600 \mathrm{~nm}$.

\section{Batch culture in the bioreactor}

Cultivations were conducted in MiniBio $500 \mathrm{~mL}$ bioreactors (Applikon Biotechnology, The Netherlands) with a working volume of $250 \mathrm{~mL}$. Pre-inocula were prepared by incubating cells in $5 \mathrm{~mL}$ of YPD for eight hours. The resulting cultures were used to inoculate secondary $10-\mathrm{mL}$ inocula to an $\mathrm{OD}_{600}=1$, which were subsequently incubated at $30{ }^{\circ} \mathrm{C}$ and $200 \mathrm{rpm}$ overnight. An aliquot of an inoculum culture was then diluted with YPG to give a $200 \mathrm{~mL}$ culture with an initial $\mathrm{OD}_{600}=1$. To prevent excess foam production, polypropylene glycol P2000 (Fisher Scientific, UK) was added to a concentration of $0.01 \%(\mathrm{v} / \mathrm{v})$ and a Rushton turbine was placed at the medium-air interface. A 20\% (v/v) dodecane (Fisher Scientific, UK) overlay was also added to minimise product loss due to air stripping. During cultivation, the temperature, dissolved oxygen and $\mathrm{pH}$ were monitored online. Biomass was measured through manual sampling twice daily. The adaptive my-Control system (Applikon Biotechnology, The Netherlands) was used to control process parameters. Setpoints of $30 \%$ of the saturation and $30^{\circ} \mathrm{C}$ were applied for dissolved oxygen and temperature, respectively. The culture $\mathrm{pH}$ was controlled to a setpoint of six through automatic addition of $1 \mathrm{M} \mathrm{NaOH}$. Samples were taken twice daily for analysis of taxane and biomass concentration.

\section{Diterpene analysis and quantification}

The dodecane overlay was analyzed by GC-MS using Trace 1300 GC (ThermoFisher Scientific), equipped with TG-SQC column $(15 \mathrm{~m} \times 0.25 \mathrm{~mm} \times 0.25 \mu \mathrm{m})$. The mass spectra in the range of $50-650 \mathrm{~m} / \mathrm{z}$ was recorded on a Thermo Scientific ISQ Series single quadrupole mass spectrometer using EI ionization mode and scan time of $0.204 \mathrm{~s}$. The GC temperature programme began at $120^{\circ} \mathrm{C}(3 \mathrm{~min})$ and was then raised to $250{ }^{\circ} \mathrm{C}$ at a rate of $20^{\circ} \mathrm{C} / \mathrm{min}$ with $3 \mathrm{~min}$ hold time. Xcalibur ${ }^{\mathrm{TM}}$ software (ThermoFisher Scientific, USA) was employed for data processing. Pure taxadiene (kindly supplied by Baran

Table 2 Yeast strains used in this study

\begin{tabular}{|c|c|c|}
\hline Strain name & Genotype & Reference \\
\hline GTy116 & $\begin{array}{l}\text { MATa, leu2-3, 112::HIS3MX6-GAL1p-ERG19/GAL10p-ERG8; ura3-52::URA3-GAL1p-MvaSA110G/GAL10p- } \\
\text { MvaE (codon optimised); his3 311::hphMX4-GAL1p-ERG12/GAL10p-IDI1; trp1-289::TRP1_GAL1p- } \\
\text { CrtE(X.den)/GAL10p-ERG20; YPRCdelta15::NatMX-GAL1p-CrtE(opt)/GAL10p-CrtE }\end{array}$ & [9] \\
\hline LRS1 & mGTy116 Yep_Gal1p-3Xflag-M60TASYBRE-CYC1 & This study \\
\hline LRS2 & mGTy116 ARS1014a::TDH3p-TASY-ADH1t & [9] \\
\hline LRS3 & mGTy116 ARS1014a::Gal1p-TASY-GFP & This study \\
\hline LRS4 & LRS3 ARS1622:: Gal1p-MBP-TASY-ERG20* & This study \\
\hline LRS5 & LRS4 ARS1114a::Gal1p-MBP-TASY-ERG20* & This study \\
\hline
\end{tabular}


Lab, The Scripps Research Institute) and geranylgeraniol (Sigma Aldrich, UK) were used as standards to identify and quantify taxadiene and GGOH, respectively. Additional taxane products were quantified relative to standard taxadiene concentrations.

\section{Intracellular taxadiene quantification}

Intracellular taxadiene accumulation was quantified in the $20{ }^{\circ} \mathrm{C}$ bioreactor samples. Cell lysis was achieved using a previously described protocol [40] with some modifications. In summary, $1 \mathrm{~mL}$ of the aqueous culture phase was centrifuged and the cell pellet was resuspended in a mixture containing $0.4 \mathrm{~mL}$ of yeast lysis reagent $(2 \%(v / v)$ Triton X100,1\% $(w / v)$ SDS, $100 \mathrm{mM}$ $\mathrm{NaCl}, 10 \mathrm{mM}$ Tris- $\mathrm{HCl}(\mathrm{pH} 8.0)$ and $1 \mathrm{mM}$ EDTA (pH 8.0)) and $0.4 \mathrm{~mL}$ of $1 \mathrm{M} \mathrm{HCl}$ for cell lysis. The resulting suspension was mixed thoroughly prior to the addition of a 1-mL dodecane overlay. The samples were subsequently incubated at $30{ }^{\circ} \mathrm{C}, 200 \mathrm{rpm}$ for $16 \mathrm{~h}$ before separation of the organic phase for GC-MS analysis.

\section{Supplementary information}

Supplementary information accompanies this paper at https://doi. org/10.1186/s12934-020-01458-2.

Additional file 1: Table S1. Plasmids used in this study. Table S2. List of primers used in the study. Table S3. DNA sequences. Figure S1. Fluorescence imaging of GFP-tagged TASY showing spotted subcellular localization consistent with poor TASY solubility. Figure S2. Mass spectra for compounds produced by LRS5. Figure S3. LRS5 gas chromatogram showing additional potential terpenoids. Figure $\mathbf{S 4}$. Mass spectra of the LRS5 additional potential terpenoids (A-D) as shown in Figure S3.

\section{Abbreviations}

BTS1: Geranylgeranyl diphosphate synthase; crtE: Geranylgeranyl diphosphate synthase; DMAPP: Dimethylallyl pyrophosphate; ERG8: Phosphomevalonate kinase; ERG9: Farnesyl-diphosphate farnesyl transferase (squalene synthase); ERG 10: 3-Hydroxy-3-methylglutaryl-CoA (HMG-CoA) synthase; ERG12: Mevalonate kinase; ERG13: 3-Hydroxy-3-methylglutaryl-CoA (HMG-CoA) synthase; ERG 19: Mevalonate pyrophosphate decarboxylase; ERG20: Farnesyl pyrophosphate synthetase; FPP: Farnesyl diphosphate; GGOH: (E,E,E)-geranylgeraniol; GGPP: (E,E,E)-Geranylgeranyl diphosphate; GPP: Geranyl diphosphate; HMG1: 3-Hydroxy-3-methylglutaryl-coenzyme A reductase 1; HMG2: 3-Hydroxy3-methylglutaryl-coenzyme A reductase 2; IDI: Isopentenyl-diphosphate delta-isomerase; IPP: Isopentenyl pyrophosphate; MBP: Maltose binding protein; mvaE: Acetyl-CoA acetyltransferase; mvaS: Hydroxymethylglutaryl-CoA synthase; TASY:Taxadiene synthase.

\section{Acknowledgements}

The authors would like to thank Professor Phil Baran's Lab at The Scripps Research Institute, San Diego, California for providing the taxadiene standard. Thanks to Ms. Caroline Delahoyde and Mr. Martin Corcoran for their kind assistance and technical support with GC-MS analysis.

\section{Authors' contributions}

$B N, R A L, L E W, L D, K M$ and AlLE performed the experiments. BN and LEW drafted the manuscript, analysed the data and prepared the figures. $\mathrm{LL}$ assisted with intracellular taxadiene measurement experiment. NJB assisted with fluorescent imaging. BN edited the manuscript. LRS, JDK and JRMR supervised the project. All authors read and approved the final manuscript.

\section{Funding}

This work was supported by The University of Edinburgh's Principal Career development Scholarship, The Engineering and Physical Sciences Research Council (Grant number: EP/R513209/1), YLSY Program of the Ministry of National Education of the Republic of Turkey, the Royal Society (Grant number: RSGIR1 180345), University of Edinburgh Global Challenges Theme Development Fund (Grant number:TDF_03), and National Institutes of Health (5 R01 AT010593-02)

\section{Availability of data and materials}

The yeast strains and plasmids described in this work will be made available upon request to the corresponding author. Data sharing is not applicable as no datasets were analysed or generated in this study.

\section{Ethics approval and consent to participate}

Ethics approval not applicable as this article does not describe any studies involving human participants or animals.

\section{Consent for publication}

Not applicable.

\section{Competing interests}

J.D.K. has financial interests in Amyris, Lygos, Demetrix, Napigen, Maple Bio, Apertor Labs, Ansa Biotechnologies, and Berkeley Brewing Sciences.

\section{Author details}

${ }^{1}$ Institute for Bioengineering, School of Engineering, The University of Edinburgh, Edinburgh EH9 3BF, United Kingdom. ${ }^{2}$ Centre for Synthetic and Systems Biology (SynthSys), The University of Edinburgh, Edinburgh EH9 3BD, United Kingdom. ${ }^{3}$ DOE Joint BioEnergy Institute, Emeryville, CA 94608, USA. ${ }^{4}$ Biological Systems and Engineering Division, Lawrence Berkeley National Laboratory, Berkeley, CA 94720, USA. ${ }^{5}$ Centro de Investigación en Biotecnología y Nanotecnología, Facultad de Ciencias Químicas, Universidad Autónoma de Nuevo León, Apodaca, Mexico. ${ }^{6}$ Departments of Chemical \& Biomolecular Engineering and of Bioengineering, University of California, Berkeley, Berkeley, CA 94720, USA. ${ }^{7}$ Center for Biosustainability, Danish Technical University, Lyngby, Denmark. ${ }^{8}$ Center for Synthetic Biochemistry, Institute for Synthetic Biology, Shenzhen Institutes for Advanced Technologies, Shenzhen, China.

Received: 19 June 2020 Accepted: 17 October 2020

Published online: 02 November 2020

\section{References}

1. McElroy $C$, Jennewein $S$. Taxol ${ }^{\circledR}$ biosynthesis and production: from forests to fermenters. In: Schwab W, Lange BM, Wüst M, editors. Biotechnol Nat Prod. Cham: Springer International Publishing; 2018. p. 145-85.

2. Frense D. Taxanes: perspectives for biotechnological production. Appl Microbiol Biotechnol. 2007;73:1233-40.

3. Köksal M, Jin Y, Coates RM, Croteau R, Christianson DW. Taxadiene synthase structure and evolution of modular architecture in terpene biosynthesis. Nature. 2010;469:116-20.

4. Jin Y, Williams DC, Croteau R, Coates RM. Taxadiene synthase-catalyzed cyclization of 6-fluorogeranylgeranyl diphosphate to 7-fluoroverticillenes. J Am Chem Soc. 2005;127:7834-42.

5. Soliman S, Tang Y. Natural and engineered production of taxadiene with taxadiene synthase. Biotechnol Bioeng. 2015;112:229-35.

6. Huang K, Huang Q, Wildung MR, Croteau R, Scott Al. Overproduction, in Escherichia coli of soluble taxadiene synthase, a key enzyme in the Taxol biosynthetic pathway. Protein Expr Purif. 1998;13:90-6.

7. Ajikumar PK, Xiao W-H, Tyo KEJ, Wang Y, Simeon F, Leonard E, et al. Isoprenoid pathway optimization for Taxol precursor overproduction in Escherichia coli. Science. 2010;330:70-4.

8. Engels B, Dahm P, Jennewein S. Metabolic engineering of taxadiene biosynthesis in yeast as a first step towards Taxol (paclitaxel) production. Metab Eng. 2008;10:201-6.

9. Reider Apel A, d'Espaux L, Wehrs M, Sachs D, Li RA, Tong GJ, et al. A Cas9based toolkit to program gene expression in Saccharomyces cerevisiae. Nucleic Acids Res. 2017:45:496-508. 
10. Kaspera R, Croteau R. Cytochrome P450 oxygenases of Taxol biosynthesis. Phytochem Rev Dordrecht. 2006;5:433-44.

11. Biggs BW, Lim CG, Sagliani K, Shankar S, Stephanopoulos G, De Mey M, et al. Overcoming heterologous protein interdependency to optimize P450-mediated Taxol precursor synthesis in Escherichia coli. Proc Natl Acad Sci. 2016;113:3209-14.

12. Delic M, Valli M, Graf AB, Pfeffer M, Mattanovich D, Gasser B. The secretory pathway: exploring yeast diversity. FEMS Microbiol Rev. 2013;37:872-914.

13. DeJong JM, Liu Y, Bollon AP, Long RM, Jennewein S, Williams D, et al. Genetic engineering of Taxol biosynthetic genes in Saccharomyces cerevisiae. Biotechnol Bioeng. 2006;93:212-24.

14. Williams DC, Wildung MR, Jin AQ, Dalal D, Oliver JS, Coates RM, et al. Heterologous expression and characterization of a"pseudomature" form of taxadiene synthase involved in paclitaxel (Taxol) biosynthesis and evaluation of a potential intermediate and inhibitors of the multistep diterpene cyclization reaction. Arch Biochem Biophys. 2000;379:137-46.

15. Huang Q, Roessner CA, Croteau R, Scott Al. Engineering Escherichia coli for the synthesis of taxadiene, a key intermediate in the biosynthesis of Taxol. Bioorg Med Chem. 2001;9:2237-42.

16. Sagwan-Barkdoll L, Anterola AM. Taxadiene-5a-ol is a minor product of CYP725A4 when expressed in Escherichia coli. Biotechnol Appl Biochem. 2018;65:294-305.

17. Li J, Mutanda I, Wang K, Yang L, Wang J, Wang Y. Chloroplastic metabolic engineering coupled with isoprenoid pool enhancement for committed taxanes biosynthesis in Nicotiana benthamiana. Nat Commun. 2019;10:1-12.

18. Hsu PD, Lander ES, Zhang F. Development and applications of CRISPRCas9 for genome engineering. Cell. 2014;157:1262-78.

19. Lee ME, DeLoache WC, Cervantes B, Dueber JE. A highly characterized yeast toolkit for modular, multipart assembly. ACS Synth Biol Am Chem Soc. 2015;4:975-86

20. Boghigian BA, Salas D, Ajikumar PK, Stephanopoulos G, Pfeifer BA. Analysis of heterologous taxadiene production in $\mathrm{K}$ - and B-derived Escherichia coli. Appl Microbiol Biotechnol. 2012;93:1651-61.

21. Abdallah II, Pramastya H, van Merkerk R, Sukrasno Quax WJ. Metabolic engineering of Bacillus subtilis toward taxadiene biosynthesis as the first committed step for Taxol production. Front Microbiol. 2019;10:218.

22. Schrepfer P, Buettner A, Goerner C, Hertel M, van Rijn J, Wallrapp F. et al. Identification of amino acid networks governing catalysis in the closed complex of class I terpene synthases. Proc Natl Acad Sci. 2016;113:E958-67.

23. Tashiro M, Ono K, Kimura Y, Kawai-Noma S, Saito K, Umeno D. Tweezing the cofactor preference of gymnosperm pinene synthase. Biosci Biotechnol Biochem. 2018;82:1058-61.

24. Kosobokova EN, Skrypnik KA, Kosorukov VS. Overview of fusion tags for recombinant proteins. Biochem. 2016;81:187-200.

25. Ignea C, Trikka FA, Nikolaidis AK, Georgantea P, loannou E, Loupassaki S, et al. Efficient diterpene production in yeast by engineering Erg20p into a geranylgeranyl diphosphate synthase. Metab Eng. 2015;27:65-75.

26. Deng Y, Sun M, Xu S, Zhou J. Enhanced (S)-linalool production by fusion expression of farnesyl diphosphate synthase and linalool synthase in Saccharomyces cerevisiae. J Appl Microbiol. 2016;121:187-95.
27. Wong J, d'Espaux L, Dev I, van der Horst C, Keasling J. De novo synthesis of the sedative valerenic acid in Saccharomyces cerevisiae. Metab Eng. 2018:47:94-101.

28. Freud Y, Ansbacher T, Major DT. Catalytic control in the facile proton transfer in taxadiene synthase. ACS Catal Am Chem Soc. 2017;7:7653-7.

29. Hayes CJ, Palframan MJ, Pattenden G. The impact of macrocycle conformation on the taxadiene-forming carbocation cascade: insight gained from sobralene, a recently discovered verticillene isomer. J Org Chem Am Chem Soc. 2020;85:4507-14.

30. Kirby J, Nishimoto M, Park JG, Withers ST, Nowroozi F, Behrendt D, et al. Cloning of casbene and neocembrene synthases from Euphorbiaceae plants and expression in Saccharomyces cerevisiae. Phytochemistry. 2010;71:1466-73.

31. van Rijn JPM, Escorcia AM, Thiel W. QM/MM study of the taxadiene synthase mechanism. J Comput Chem. 2019;40:1902-10.

32. Song $T-Q$, Ding M-Z, Zhai F, Liu D, Liu H, Xiao W-H, et al. Engineering Saccharomyces cerevisiae for geranylgeraniol overproduction by combinatorial design. Sci Rep. 2017;7:14991.

33. Huang Q, Williams HJ, Roessner CA, Scott Al. Sesquiterpenes produced by truncated taxadiene synthase. Tetrahedron Lett. 2000;41:9701-4.

34. Edgar S, Li F-S, Qiao K, Weng J-K, Stephanopoulos G. Engineering of taxadiene synthase for improved selectivity and yield of a key Taxol biosynthetic intermediate. ACS Synth Biol Am Chem Soc. 2017;6:201-5.

35. Arhar $\mathrm{S}$, Natter K. Common aspects in the engineering of yeasts for fatty acid- and isoprene-based products. Biochim Biophys Acta-Mol Cell Biol Lipids. 2019;1864:158513.

36. Sun L, Shang F, Duan C, Yan G. Reduction of fatty acid flux at low temperature led to enhancement of $\beta$-carotene biosynthesis in recombinant Saccharomyces cerevisiae. Korean J Chem Eng. 2015;32:1354-60.

37. Ker D-S, Pang SL, Othman NF, Kumaran S, Tan EF, Krishnan T, et al. Purification and biochemical characterization of recombinant Persicaria minor ß-sesquiphellandrene synthase. PeerJ. 2017;5:e2961-e2961.

38. Aguilar F, Scheper T, Beutel S. Modulating the precursor and terpene synthase supply for the whole-cell biocatalytic production of the sesquiterpene (+)-Zizaene in a pathway engineered E. coli. Genes. 2019;10:478.

39. Gietz RD, Schiestl RH. High-efficiency yeast transformation using the LiAc/SS carrier DNA/PEG method. Nat Protoc. 2007;2:31-4.

40. Westfall PJ, Pitera DJ, Lenihan JR, Eng D, Woolard FX, Regentin R, et al. Production of amorphadiene in yeast, and its conversion to dihydroartemisinic acid, precursor to the antimalarial agent artemisinin. Proc Natl Acad Sci USA. 2012;109:E111-8.

41. Zhang M, MCLaughlin JA, Wipat A, Myers CJ. SBOLDesigner 2: An intuitive tool for structural genetic design. ACS Synth Biol. 2017;6:1150-60.

\section{Publisher's Note}

Springer Nature remains neutral with regard to jurisdictional claims in published maps and institutional affiliations.

\footnotetext{
Ready to submit your research? Choose BMC and benefit from:

- fast, convenient online submission

- thorough peer review by experienced researchers in your field

- rapid publication on acceptance

- support for research data, including large and complex data types

- gold Open Access which fosters wider collaboration and increased citations

- maximum visibility for your research: over $100 \mathrm{M}$ website views per year
}

At BMC, research is always in progress.

Learn more biomedcentral.com/submissions 